It would seem that if only the early stages could be recognized measures could be taken to avoid the final degradation. This presupposes that the patient would accept help, though we are by no means certain that this is necessarily true, even in the early stages.

We tried to obtain information about the time of onset and the first signs from relatives and neighbours in all cases, but found it difficult to obtain accurate data. In 34 cases no one could state exactly when deterioration had shown itself. In the others the period varied from one year to 10 . There was, however, absolutely no connexion between the duration and the degree of social deterioration. Cases of one year's duration were just as bad as those with a much longer history.

The vulnerable individuals "at risk," who are potential candidates for developing the syndrome and in whose cases preventive community measures ought to be taken, are old people of the independent and domineering type living alone, with poor or non-existent social links with their local community. Their personality makes contact with them difficult, but much can be done with tact and perseverance, and this should be an easier task in the pre-breakdown stage.

The key figures in prevention are the family doctor and community workers, such as the health visitor, the welfare services visitor, and the mental welfare officers, as they are usually the first to become aware of the situation. They should be alive to the importance of precipitating factors-bereavement and physical ill-health or trauma, for instance.

There is usually no organization to which cases can be reported and from which efficient action can be obtained. Our survey has demonstrated the need for such a service to be made available for these cases. We would like to suggest that in every area someone, preferably medical, should be designated to deal with all such cases from both the preventive and the therapeutic aspects. Psychiatric advice should be available.

The question arises why old people, exposed to apparently comparable stresses, develop different patterns of symptoms. In some instances there is this syndrome of senile breakdown in standards, in others a senile paranoid psychosis, and in yet others one of the psychiatric senile states which are at present lumped together under the diagnosis of senile psychosis or senile dementia, while others show no obvious abnormal symptoms.

Why in some cases do we find both the syndrome and a psychiatric illness, whereas in others the syndrome occurs without psychotic symptoms?

The contrast between the environmental conditions of the senile paranoid individual retaining a scrupulous regard for standards of cleanliness and hygiene and the sufferer from the breakdown syndrome is a most striking one. More extensive investigation of the latter could throw further light on the psychoses of the senium.

We regard this investigation as merely a preliminary one of a condition which requires and should repay further study.

\section{Summary}

A group of 72 individuals exhibiting evidence of personal and environmental lack of hygiene and deterioration in social standards was studied over a period of four years.

The incidence was of the order of 0.5 per 1,000 population over 60 . Most of the patients were over 70 years old, and women far outnumbered men.

Isolation, a certain type of personality, bereavement, and alcoholism were found to be important factors in causation. Slightly over half the patients showed psychotic symptoms.

There is often a positive rejection of society and resistance to offers of help. It is suggested that the condition may be considered as a syndrome.

We have pleasure in expressing our thanks to the general practitioners and community workers who cooperated with us; to Dr. J. Kamieniecki, senior clinical psychologist to Mapperley Hospital ; Professor A. R. Emerson, of the University of East Anglia ; Dr. A. J. Willcocks, of the Nottingham University ; and to the medical, nursing, and secretarial staff of Mapperley Hospital.

\title{
Jejunal Disaccharidases and Some Observations on the Cause of Lactase Deficiency
}

\author{
H. B. MCMICHAEL,* M.B., M.R.C.P. ; JOAN WEBB, $†$ B.SC. ; A. M. DAWSON, $\ddagger$ M.D., F.R.C.P.
}

Brit. med. F., 1966, 2, 1037-1041

Borgström et al. (1957) confirmed that the final stage of disaccharide hydrolysis in man takes place within the small-gut mucosal cells rather than in the lumen. Mucosal disaccharidase deficiencies were then soon discovered in children (Durand, 1958 ; Holzel et al., 1959), and now lactase deficiency is well recognized in adults (Dahlqvist et al., 1963 ; Auricchio et al., 1963a ; Haemmerli et al., 1965; Cuatrecasas et al., 1965; McMichael et al., 1965), although its cause remains obscure. Mucosal damage depresses lactase activity (Schmerling et al., 1964 ; Plotkin and Isselbacher, 1964), but the relevance of this observation to lactase deficiency in structurally normal mucosa is uncertain. 'Inheritance of disaccharidase deficiencies has been discussed by Dahlqvist (1962) on the basis of enzyme charac-

\footnotetext{
* Research Assistant.

+ Biochemist.

$\$$ Physician.

St. Bartholomew's Hospital, London, and the Medical Unit, the Royal Free Hospital, London.
}

terization, but while inheritance of sucrase deficiency is now fairly well established (Auricchio et al., 1965b) there are few data on the inheritance of lactase deficiency.

We have therefore analysed the disaccharidase activities of 87 consecutive peroral jejunal biopsies, 18 of which were structurally abnormal, and performed lactose-tolerance tests in a further 15 subjects in an attempt to clarify the origin of lactase deficiency in adults with structurally normal mucosa.

\section{Methods and Material}

Eighty-seven jejunal biopsies were taken by Crosby capsule from 86 patients who had diarrhoea, abdominal pain, bone disease, or unexplained anaemia. Twelve of these patients who had previously undergone gastric surgery had biopsies taken from the second loop of jejunum; all other specimens were 
taken from the first loop. Part of each biopsy was deep-frozen to $-25^{\circ} \mathrm{C}$. within five minutes of removal, and the remainder was examined under a dissecting microscope and histologically.

Eighteen of these biopsies were structurally abnormal, and were further subdivided into those showing " mild," " moderate," or "severe" damage of the mucosa. Five showed severe damage, being of the "mosaic" pattern such as is found in gluten-induced enteropathy, and two of these patients have so far been shown to have improved biopsies after a gluten-free diet. The improved biopsy of one of these was obtained after the completion of the present enzyme study, and the other is included in the moderate-damage group, in which stunted fused villi were found. All six biopsies in this moderatedamage group were from patients on a gluten-free diet who had had previous flat biopsies. The other seven biopsies showed mild changes, with slight shortening of the villi and increased cellular infiltration in the lamina propria. The cause of this mild damage was not always clear, but one biopsy came from near the stoma in a patient with a gastroenterostomy, and a further two came from patients with chronic liver disease. Two other patients came from Central Africa and one patient from India ; no parasites were found in the stools of these patients.

Further biopsies were obtained at laparotomy from 14 unselected patients undergoing gastrointestinal surgery. For the disaccharidase assay mucosa was scraped off the serosa with a knife. These surgical biopsies are discussed separately.

Disaccharidase activities were determined by the method of Burgess et al. (1964) by incubating whole homogenate of intestinal mucosa in 0.04 molar substrate solution at $\mathrm{pH} 6$ for 20 minutes at $37^{\circ} \mathrm{C}$. Zero-order kinetics were demonstrated for this short incubation time, but were not maintained for incubation periods of longer than 25 minutes at this substrate concentration. Glucose liberated was measured by glucose oxidase (Boehringer pack) in a tris buffer solution. Results are expressed in "units" of $\mu$ mols disaccharide hydrolysed/ minute/gram tissue wet weight at $37^{\circ} \mathrm{C}$.

Maltase and lactase activities were measured in all specimens, but sucrase, palatinase, and trehalase were not determined in one, four, and seven biopsies respectively owing either to lack of substrate or to inadequate size of the specimens.

Two biopsies are omitted from the results given because, although no structural abnormality has been demonstrated, four out of five and five out of five of the disaccharidases assayed respectively were less than the -2 S.D. range. Other observations in these two patients suggest that they have a true carbohydrate intolerance as yet poorly understood, and it is hoped to study them further. One of these two patients had had a partial gastrectomy.

Lactose-tolerance tests were performed with a standard 50-g. lactose load. Blood sugars were estimated on an autoanalyser by the micro-glucose method adapted from Hoffman (1937). Twenty-five out of 26 patients with known normal mucosal lactase activity who had a lactose-tolerance test had a maximum blood-sugar rise of at least $25 \mathrm{mg} . / 100 \mathrm{ml}$. (see Fig. 5). ' Lower blood-sugar rises are therefore taken to indicate lactose malabsorption.
In a racial study investigation was made of 17 Greek Cypriot patients, of whom nine were in hospital for non-gastroenterological disease, and selected only because of their race. Two others had peptic ulcers, one had ulcerative colitis, and another had chronic liver disease. The other four subjects were the wife and one child of one of the above and two children of another.

\section{Results}

\section{Disaccharidase Activities in Structural Normal Biopsies}

Each of the disaccharidase activities follows a log normal distribution, and so the median and range have been calculated by taking the antilog of the mean and the (mean \pm 2 standard deviations) of the $\log _{10}$ natural units. The results are shown in the Table.

Lactase.-When a frequency distribution histogram of the log jejunal lactase activity is plotted (Fig. 1) there are clearly two populations, each of which may be shown to approximate to a normal distribution by plotting observed frequency against probability (Figs. 2 and 3 ). The normal lactase range is found to be 3.4-18.6 units and the range of hypolactasia 0.1-2.8 units. Of the 11 post-gastrectomy patients, two had hypolactasia and nine were normal-a similar incidence of lactase deficiency to that found in other biopsies. The other four disaccharidase activities measured were similar in the normal and the lactase-deficient patients, so that non-specific enzyme depression was excluded as the cause of lactase deficiency in these biopsies.

Maltase.-A frequency distribution histogram of log maltase activity shows a positive skew if results from all structurally normal biopsies are included-Karl Pearson's measure of skewness $\left(\frac{\text { mean-mode }}{\text { standard deviation }}=0.348\right)$. This skew was greatly decreased if post-gastrectomy patients were omitted $\left(\frac{\text { mean }- \text { mode }}{\text { standard deviation }}=0.189\right)$. The remaining results approximate well to a normal distribution, and give a range of 24.5-77.6 natural units. The post-gastrectomy patients have a significantly higher range $(39.8-144)(P<0.001)$.

Sucrase and Palatinase.-The normal range of sucrase activity is 6.9-28.8 and of palatinase 1.5-9.6. One patient, who

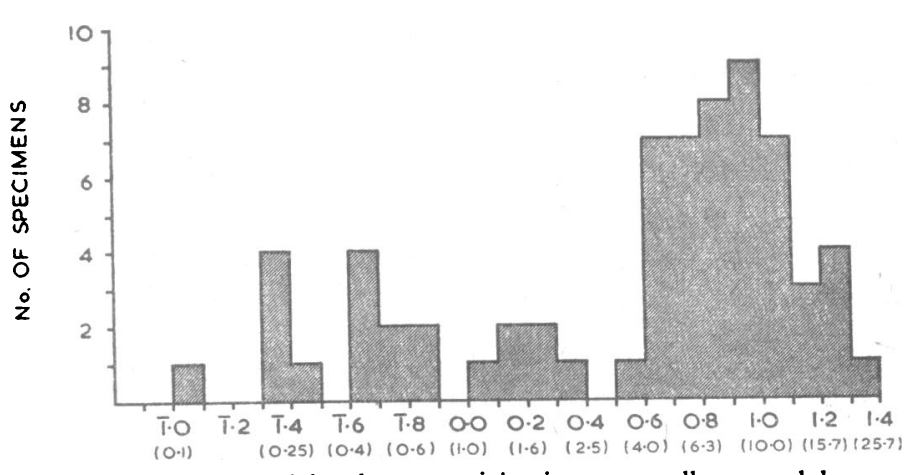

FIG. 1.-Histogram of $\log$ lactase activity in structurally normal human jejunum. Natural units in parenthesis.

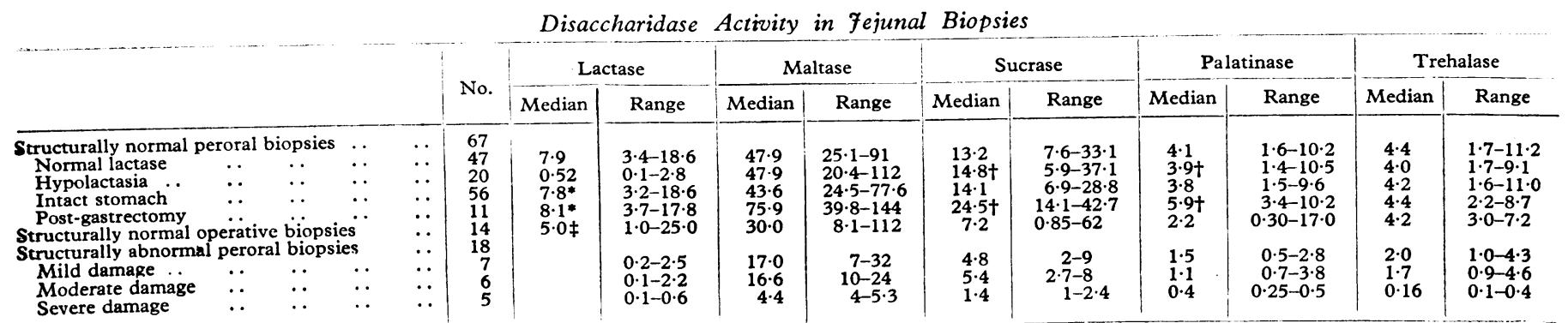


had had gastric surgery, had a sucrase activity of 2.4 units and a palatinase activity of 1.0 unit (log activities are 8 and 6 standard deviations respectively below the mean log activities for post-gastrectomy patients). She also had lactase deficiency, but maltase and trehalase activities were normal. Her sucrase

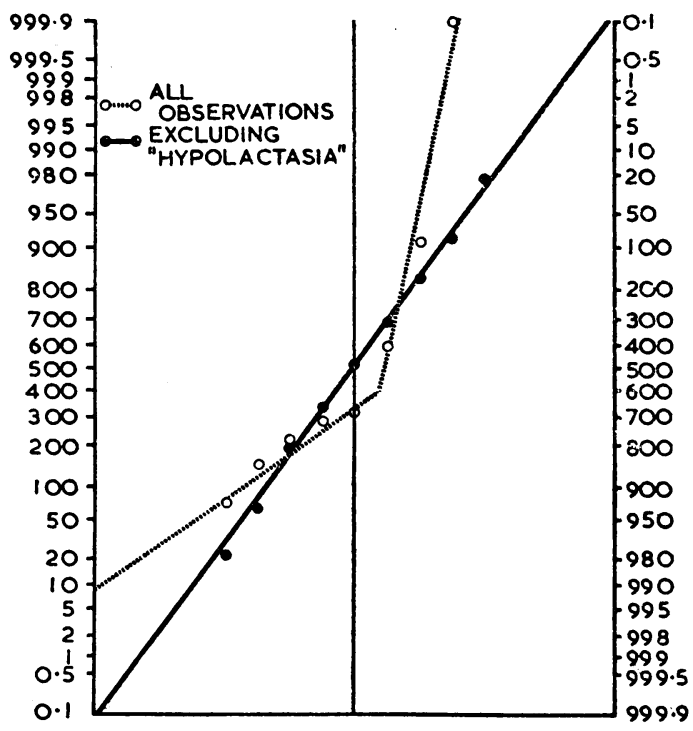

FIG. 2.-Probability distribution plot of log lactase activity in structurally normal human jejunum. All patients produce skew line; "normal" lactase patients fail on straight normal probability line.

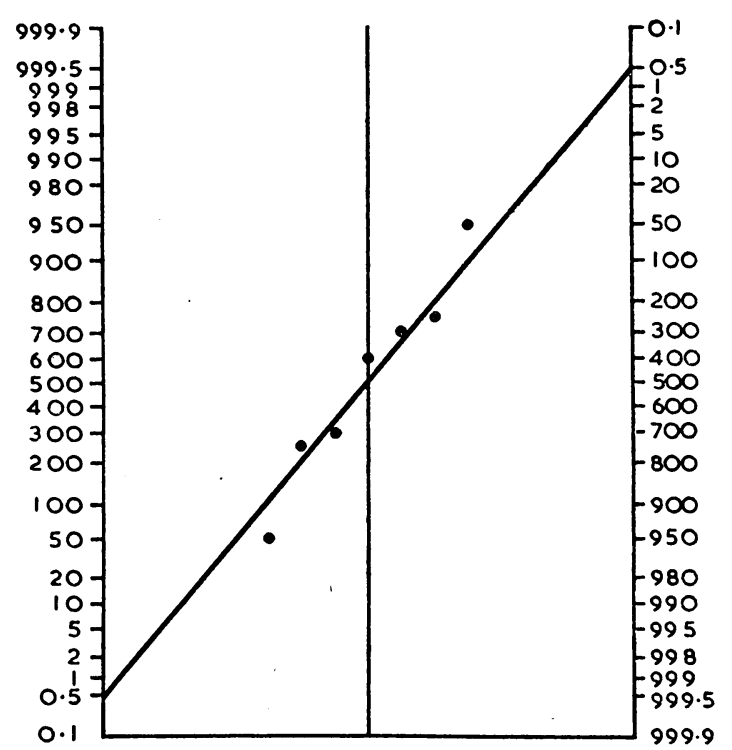

FIg. 3.-Probability distribution plot of log lactase activity in "hypolactasia" patients. These approximate to straight normal probability line.

and palatinase results are omitted from the Table. As with maltase, the activities found in biopsies from post-gastrectomy patients are significantly higher than those from other patients (sucrase, $\mathrm{P}<0.001$; palatinase, $\mathrm{P}<0.005$ ). .

Trehalase.-The normal range is $1.6-11.0$ units. There was no difference between patients who had had a partial gastrectomy and those who had not, demonstrating that the postgastrectomy effect is confined to maltase, sucrase, and palatinase.

\section{Disaccharidase Activities in Structurally Abnormal Biopsies}

All disaccharidase activities are depressed (see Table) and are consistently lowest in biopsies showing severe damage.
Lactase.-No mean, median, standard deviation or range has been calculated, for the following reasons. First, it may be expected that the lactase activities found represent a double population, and so a mean is of no significance. Secondly, in two out of five "flat" biopsies and one out of six moderately damaged biopsies the lactase activity was too low to be measured by our technique, which means that the activity was less than 0.2 natural unit. Activities of 0.1 natural unit have been assumed for these three biopsies, since to omit them would be a bias in favour of higher activities, while to consider them as zero is probably untrue, and $\log \mathrm{O}$ is infinity, which makes them difficult to incorporate. It should be emphasized, however, that even if this estimate of 0.1 unit is too high, taking a lower activity would make no difference to any conclusion drawn. The actual ranges found are shown in the Table.

Maltase, Sucrase, Palatinase, Trehalase.-Calculated medians and actual ranges are shown in the Table. The depression of these enzymes is not as great as that of lactase, but this is better shown by determining enzyme ratios.

\section{Enzyme Ratios}

Log maltase/lactase activities are shown in Fig. 4. The log ratios of the structurally normal biopsies approximate to two normally distributed populations with a range of natural ratios for normal subjects (post-gastrectomy patients omitted) of 2.611.5, and for hypolactasia subjects of 13.2-575. In practice,

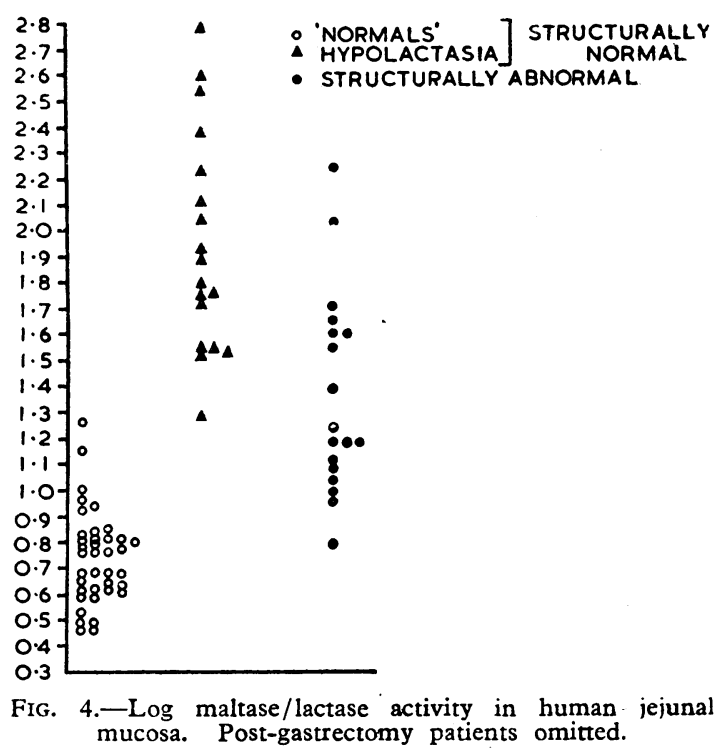

however, this does not give as reliable separation of normal and deficient lactase as the absolute lactase activities. Three normal subjects with a high maltase have maltase/lactase ratios outside the normal range, one having a ratio of 18 . That she is correctly classified as normal is shown by a blood-sugar rise after $50 \mathrm{~g}$. of lactose of $97 \mathrm{mg} . / 100 \mathrm{ml}$.

When enzyme ratios are calculated for the structurally abnormal biopsies, those between maltase, sucrase, palatinase, and trehalase are very similar to the corresponding ratios found in structurally normal biopsies, but those involving lactase are strikingly different, and demonstrate that lactase is more depressed by mucosal damage than are the other disaccharidases. Log maltase/lactase activities of structurally abnormal biopsies are contrasted in Fig. 4 with the ratios found in the normal and hypolactasia populations. Clearly the ratios found in structurally abnormal biopsies overlap the upper end of the normal range and the lower end of the hypolactasia range. If the estimate of 0.1 natural unit for the three low-activity biopsies is too high, the distribution would be altered to include the full 
hypolactasia range, but the overlap with the upper normal range would remain. The conclusion to be drawn is that lactase is more depressed by structural damage than maltase, but not sufficiently depressed relative to maltase to fit well into the hypolactasia range. The maltase/lactase ratios of the structurally abnormal biopsies differ significantly from the hypolactasia group $(\mathrm{P}<0.001)$.

\section{Operative Biopsies}

Results are shown in the Table. Three patients had lactase deficiency with low lactase activities in the biopsies, high maltase/lactase ratios, and flat lactose-tolerance tests.

The median lactase, maltase, sucrase, and palatinase activities of the operative biopsies are lower than those of the peroral biopsies. The range of activities found is also much wider.

Trehalase activity differs markedly in that the median is the same as that of the peroral biopsies, and the range found is actually smaller. This finding is unexplained.

\section{Racial Study}

Two of the cases of biopsy-proved lactase deficiency were Greek Cypriots, and both gave positive family histories of milk intolerance. It was then brought to our notice that many Greeks suffer from milk intolerance (N. Moskoutis, personal communication, 1964). It was not thought justifiable to take jejunal biopsies for a racial study, but lactose-tolerance tests were done on all Greek Cypriot patients available to us. They were questioned with regard to possible symptoms only after the test had been done.

Fig. 5 shows the fairly good separation of normal and hypolactasia groups obtained by measuring the maximum bloodsugar rise after a 50-g. oral lactose load. Fifteen of the 17

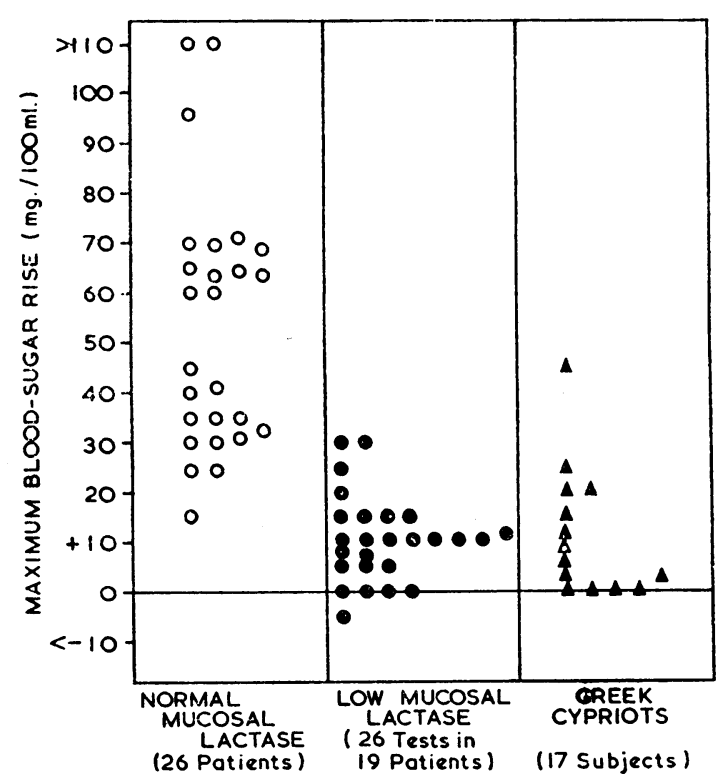

Fig. 5.-Maximum blood-sugar rise after $50 \mathrm{~g}$. of oral lactose.

Greek Cypriots tested showed a blood-sugar rise of $20 \mathrm{mg}$./ $100 \mathrm{ml}$. or less, which is highly suggestive of lactase deficiency. Five of these patients have had a glucose/galactose-tolerance test ( $25 \mathrm{~g}$. of each monosaccharide), with a mean maximum blood-sugar rise of $50 \mathrm{mg} . / 100 \mathrm{ml}$., showing that the flat lactose-tolerance curves are unlikely to be due to mucosal damage.

\section{Discussion}

Although the disaccharidase activities found agree closely with those of Dahlqvist et al. (1963), Auricchio et al. (1963b), and Burgess et al. (1964), the methods of enzyme assay vary so greatly that results from different centres cannot easily be compared. For example, Dahlqvist (1964) homogenizes the mucosa, centrifuges, and then uses the supernatant, while Peternel (1965) uses whole homogenate; $\mathrm{pH}$ varies from 5.6 (Sheehy and Anderson, 1965) to 6.25 (Plotkin and Isselbacher, 1964); substrate concentration varies from $0.028 \mathrm{M}$ (Dahlqvist, 1964) to $0.056 \mathrm{M}$ (Sheehy and Anderson, 1965); and incubation times vary from 20 minutes (Burgess et al., 1964) to 60 minutes (Auricchio et al., 1963b). Until the methods are more standardized, it will be necessary for each centre to determine its own normal range and to ensure that it is working under conditions of zero-order kinetics. The low normal lactase range found by Sheehy and Anderson (1965) emphasizes this, and it may be significant that they used a low $\mathrm{pH}$, a high substrate concentration, and a long incubation period. The lower activities and wider range found in operative biopsies agree with the findings of Auricchio et al. (1963b). Operative biopsy results cannot therefore be directly compared with those from peroral biopsies.

Many workers-for example, Auricchio et al. (1963b) and Plotkin and Isselbacher (1964)-express their results per gram of protein, but the range of activities found is no smaller, and this extra measurement appears to have no advantage (Sheehy and Anderson, 1965).

The use of logarithms facilitates interpretation by giving a statistically normal distribution. In spite of the small numbers available the hypolactasia activities approximate to a log normal distribution, with a totally different range from normal. Immediately, therefore, one can exclude the idea that low lactase activities represent only the lowest tail of the normal lactase range (Haemmerli et al., 1965). The plotting of a frequencydistribution histogram of $\log$ maltase activity revealed an unexpected skew-which turned out to be due to the postgastrectomy patients; the presence of an unexpected variant may be revealed by using logs. The calculation of a mean and standard deviation enables the abnormal to be defined statistically. This applies not only to lactase deficiency, but also, for example, to the enzyme activities of the patient with sucrase and palatinase deficiency, which on an arithmetical distribution plot might have been within a " normal tail."

The higher maltase, sucrase, and palatinase activities after a partial gastrectomy may be induced by frequent large loads of starch entering the upper jejunum. However, since these biopsies came from the second loop of jejunum while all the others came from the first, this finding may represent a regional variation in disaccharidase activities.

It is suggested that " primary" lactase deficiency, as found in structurally normal biopsies, is inherited. The findings of Cuatrecasas et al. (1965) indicate a high incidence in negroes, and those of Jeejeebhoy et al. (1964) a high incidence in Indians. Many Greeks have milk intolerance, so we surveyed a small number of Greek Cypriots-in effect 14 unselected propositi and three children-and found a very high incidence of lactose malabsorption in these. Such racial differences may explain the variation found in the reported incidence of lactase deficiency (Sheehy and Anderson, 1965). It is unlikely to be accounted for by dietary variation, because the lactose intake does not influence mucosal lactase in fowl, rabbits, rats, guineapigs, or pigs (Plimmer, 1906), in rats fed $60 \%$ of their calories as lactose (Fischer, 1957), or in a short study in man (Cuatrecasas et al., 1965).

None of the lactase-deficient adults studied were known to have had diarrhoea in infancy, but absence of symptoms in childhood does not exclude an inherited enzyme defect. In pigs (Bailey et al., 1956) mucosal lactase activity decreases. 
markedly after the first few weeks of life, so that older pigs get diarrhoea if fed on milk. In pigs, also, sucrase activity increases after "infancy," so that sucrose intolerance is common only in the very young. The improvement with age of human infants who have sucrose intolerance may be due to a similar agedependent enzyme change. Auricchio et al. (1965a) have shown a slight increase of total mucosal lactase activity in human neonates, but the differences compared with adults are small. Such a study in neonates might be more rewarding in a racial group known to have a high incidence of adult lactase deficiency, because a minor racial variation may cause the enzyme to regress with age. Further work on enzyme characterization in lactase deficiency may also be worth while, for in the one case so far reported (Auricchio et al., 1965b), lactase I was absent, while lactase II was present in normal amounts. Since lactase $I$ is usually the more active, little is known of the behaviour of lactase II, and it is possible that lactase II is normally high at birth and regresses with age.

If the lactase deficiency of the structurally normal biopsy is inherited, what then is the aetiological and functional significance of disaccharidase depression in structurally damaged mucosa ? Plotkin and Isselbacher (1964) emphasized that mucosal damage must be excluded before diagnosing "primary" lactase deficiency, and Schmerling et al. (1964) demonstrated that lactase is more depressed by mucosal damage than are the other disaccharidases. The findings of these workers are fully supported by the data presented. The functional significance of disaccharidase depression must be related to the "sugar pump" (Crane, 1960)-in other words, hydrolysis of disaccharides is of no use if the damaged mucosa is incapable of transporting the resultant monosaccharides. The flat glucose-tolerance test and the results of monosaccharide perfusion studies in coeliac disease (Holdsworth and Dawson, 1965) confirm impairment of the sugar pump. Only by determining in vivo hydrolysis and absorption kinetics can it be decided which stage is rate-limiting. A clinical trial of a lactose-free diet (Arthur et al., 1966) does not clarify the question ; first, because the common "primary" lactase deficiency may frequently be superimposed on mucosal damage, and, secondly, because in reducing lactose (and/or sucrose) intake total carbohydrate may be reduced and thus decrease the load on the sugar pump.

It is commonly believed that repeated mucosal damage may produce lactase deficiency. Even in the presence of mucosal damage, lactase depression relative to maltase is insufficient to bring the maltase/lactase ratio into the range found in primary lactase deficiency. It is unlikely, therefore, that mucosal damage is of any significance in the aetiology of primary lactase deficiency.

\section{Summary}

Disaccharidase activities were measured in mucosa from 87 peroral jejunal biopsies, 18 of which were structurally abnormal.

Results were found to be distributed lognormally.

In 20 biopsies that were structurally normal lactase activities fell within a well-defined " hypolactasia" range.
Enzyme activities from 14 operative jejunal biopsies were lower and varied more widely than those from peroral biopsies.

Fifteen out of 17 Greek Cypriots whose lactose tolerance was tested had lactase deficiency. Evidence of a racial incidence is presented suggesting that "primary" lactase deficiency is inherited.

Results from tests on structurally damaged mucosa suggest that mucosal damage does not cause lactase depression of the degree found in primary hypolactasia.

Maltase, sucrase, and palatinase activities are significantly higher than normal in biopsies taken from patients who had had gastric surgery.

We wish to thank Professor D. N. Baron and his staff in the Chemical Pathology Laboratory for estimating blood sugars, and the physicians and surgeons at the Royal Free Hospital who allowed us to investigate the Greek Cypriot patients under their care.

This work was supported by a grant from the Medical Research Council and the Endowment Fund of St. Bartholomew's Hospital.

\section{REFERENCES}

Arthur, A. B., Clayton, B., Cottom, D. G., Seakins, J. W. T., and Platt, J. W. (1966). Lancet, 1, 172.

Auricchio, S., Rubino, A., Landolt, M., Semenza, G., and Prader, A. (1963a). Ibid., 2, 324.

- Mürset, G. (1965a). Pediatrics, 35, 944.

- Prader, A., Rey, J., Jos, J., Frézal, J., and Davidson, M (1965b). F. Pediat., 66, 555.

- Tosi, R., Semenza, G., Landolt, M., Kistler, H., and Prader, A. (1963b). Enzym. biol. clin. (Basel), 3, 193.

Bailey, C. B., Kitts, W. D., and Wood, A. J. (1956). Canad. F. agric. Sci., 36, 51.

Borgström, B., Dahlqvist, A., Lundh, G., and Sjövall, J. (1957). 7. clin. Invest., 36, 1521.

Burgess, E. A. Levin, B., Mahalanabis, D., and Tonge, R. E. (1964) Arch. Dis. Ckildh., 39, 431.

Crane, R. K. (1960). Physiol. Rev., 40, 789.

Cuatrecasas, P., Lockwood, D. H., and Caldwell, J. R. (1965). Lancet, 1, 14.

Dahlqvist, A. (1962). f. clin. Invest., 41, 463.

- (1964). Analyt. Biochem., 7, 18.

- Hammond, J. B., Crane, R. K., Dunphy, J. V., and Littman, A. (1963). Gastroenterology, 45, 488.

Durand, P. (1958). Minerva pediat., 10, 706.

Fischer, J. E. (1957). Amer. F. Physiol., 188, 41.

Haemmerli, U. P., Kistler, H., Ammann, R., Marthader, T., Semenza, G., Auricchio, S., and Prader, A. (1965). Amer. F. Med., 38, 7.

Hoffman, W. S. (1937). F. biol. Chem., 120, 51.

Holdsworth, C. D., and Dawson, A. M. (1965). Gut, 6, 387.

Holzel, A., Schwarz, V., and Sutcliffe, K. W. (1959). Lancet, 1, 1126.

Jee;eebhoy, K. N., Desai, H. G., and Verghese, R. V. (1964). Ibid., 2, 666.

McMichael, H. B., Webb, J., and Dawson, A. M. (1965). Ibid., 1, 717.

Peternel, W. W. (1965). Gastroenterology, 48, 299.

Plimmer, R. H. A. (1906). F. Physiol. (Lond.), 35, 20.

Plotkin, G. R., and Isselbacher, K. J. (1964). New Engl. f. Med., 271, 1033.

Schmerling, D. H., Auricchio, S., Rubino, A., Hadorn, B., and Prader, A. (1964). Helv. paediat. Acta, 19, 507.

Sheehy, T. W., and Anderson, P. (1965). Lancet, 2, 1. 